\title{
A CASE OF UNIOCULAR PARALYSIS OF THE
} ACCOMMODATION

\author{
BY \\ Dr. H. J. Flieringa \\ ROTTERDAM
}

TowarDs the end of June, 1923, a child, ten years of age, was brought to see me by her mother, acting on the advice of her school teacher, to see if a sudden recent marked deterioration in her writing might be due to some ocular defect. Specimen writing from her copy-book showed an extraordinary change in two or three days. No history of recent illness was obtainable on first inquiry.

Examination of the eyes gave the following result :

The pupils were equal and reacted normally to light and convergence. There was no paresis of any of the external ocular muscles and the fundus oculi was normal. The refraction of both eyes was emmetropic and the binocular vision as well as the vision of each eye separately was 10/10. Binocularly Snellen 0.5 could be read fluently at $15 \mathrm{~cm}$. When, however, the near vision of each eye was tested separately it was found that while the left eye could now read the same type at $7.5 \mathrm{~cm}$., thus possessing an accommodation of 13 dioptres, the right eye could not read the small type at all and appeared to possess an accommodative power of only 1.5 dioptres.

The explanation of the bad writing is evidently the uniocular paralysis of the accommodation. A child, when writing, and especially when writing obliquely, tends to hold the head very much to one side, so that in the case of right-handed children, the right eye is nearer to the paper than the left one. In fixing an object in the median plane we naturally accommodate most exactly with the eye that is nearest the point of fixation so that in writing the "leading eye," in this case the right one, has done the main part of the work. Unequal accommodation does not seem to occur under normal conditions. If in this child the right eye is closed and the head is turned to the right, writing becomes once more normal. Doubtless, if the paralysis had persisted, the child would have learned to use the left eye as the "leading eye."

A point of interest in the near vision tests is the fact that while Snellen 0.5 can be read at $15 \mathrm{~cm}$. with both eyes uncovered, it cannot be read at $50 \mathrm{~cm}$. until the right eye has been occluded. This, I consider, must be due to the fact that at the greater distance the difference between the accommodation of the 
two eyes is less marked as is also the difference between the sharpness of the two ocular images. Consequently the hazy vision of the right eye will cause more inconvenience at a great distance than at a short one. At a short distance the image of the right eye will be so hazy that, psychically, it may be eliminated. No divergence was observed.

On further pressure the mother recollected that the child had been kept in bed for a few days with fever and sore throat some six weeks previously. The doctor in attendance had taken a swab but failed to find any diphtheria bacilli. In spite of this one negative result I am convinced that the patient had suffered from a mild attack of diphtheria, all the more so as I saw another girl

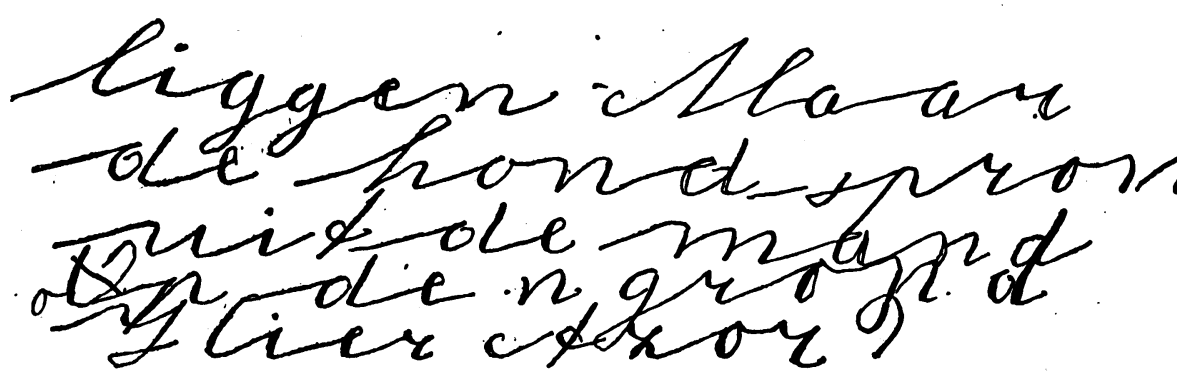

FIG. 1.

Writing during paralysis.

from the same neighbourhood a few days later with binocular paralysis of the accommodation following a sore throat.

The diagnosis was rendered a little difficult by the absence of any of the more usual forms of post-diphtheritic paralysis, by the affection-possibly only apparently-being confined to one eye, and by the normal distant vision, owing to the fact that there was no error of refraction.

Normal pupil reactions are the rule in post-diphtheritic paralysis but cases of diminished reflex to light (Scheby-Buch(1), Moll(2), Weber ${ }^{(3)}$, Schmidt-Rimpler ${ }^{(4)}$ and to convergence (Aubertin ${ }^{(5)}$, Lohmann ${ }^{(6)}$, Stephenson ${ }^{(7)}$ have been recorded.

Groenouw, writing in Graefe-Saemisch, says that both eyes are always affected, and $\operatorname{Remak}^{(8)}$ records 100 cases without a single uniocular paralysis.

In spite of these observations and the fact that the punctum proximum of the left eye, in the case here recorded, was at $7.5 \mathrm{~cm}$. (an accommodation of 13 dioptres), which corresponds with the well-known curve of Donders, I still consider that the affection 
was of a post-diphtheritic nature. In a recent paper, written in collaboration with Professor van der Hoeve ${ }^{(9)}$ (Brit. Jl. of Ophthal., March, 1924), on the study of accommodation, we have endeavoured to show that the normal ciliary muscle is able to produce a greater force than is necessary for maximum accommodation, that is to say, that the total strength of the ciliary muscle in myodioptres is greater than the number of dioptres in maximum accommodation. The older the person the greater the difference between these two values. We found in examining the total strength of the ciliary muscle values as high as or even higher than 20 myodioptres. If we accept such a value for the ciliary muscle in this patient, it is obvious that the total strength of the muscle may have been reduced by $\tau$ myodioptres without any effect on the punctum proximum. Thus, as I suppose to have been the case in my

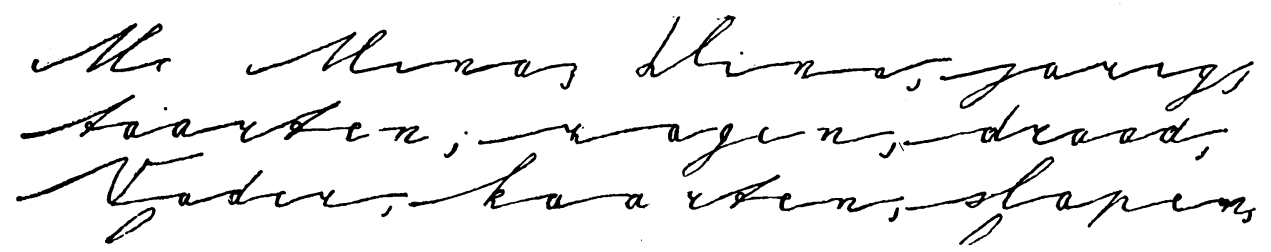

FIG. 2.

Normal writing.

patient, we may have uniocular paralysis of accommodation as found by measurement of the near-point, but a binocular affection of the ciliary muscle, provided that the amount of paralysis was not sufficient in one eye to affect the position of the near-point. A case of Wiegmann's ${ }^{(10)}$, a boy, 12 years old, well illustrates the different degree in which the diphtheria toxin may affect the two eyes. The post-diphtheritic paralysis in this case was obvious three years after infection in the right eye but had completely disappeared in the left.

I think the possibility that the left eye had been affected earlier and had recovered when I first saw the child may be excluded as reading had not been affected.

The fact that the right. eye should have been affected may possibly be explained on Edinger's $\mathbf{s}^{(1)}$ statement that a toxic paralysis prefers to manifest itself in that region of a nerve path in which most work is done, as the right eye is more used than the left in right-handed persons. On the other hand the accommodative work is always the same in both eyes.

The subsequent history of my case was the usual one in postdiphtheritic paralysis. The accommodation was restored after 
about six weeks and the punctum proximum of both eyes was then found to be $7 \mathrm{~cm}$. The writing is now quite normal again.

\title{
BIBLIOGRAPHY
}

1. Scheby-Buch.-Arch.f. Ophthal., p. 265, 1871.

2. Moll.-Centralbl.f. prakt Augenheilk, p. 2, 1896.

3. Weber.-Virchow's Arch., Vol. XXV, p. 114b, and Vol. XXVIII, p. 489, 1863.

4. Schmidt-Rimpler.-Klin. Wochenschr., p. 92, 1884. Berlin.

5. Aubertin.-Rev. Gén. d'Ophtal., p. 280, 1903.

6. Lohmann.-Bericht über d. Vers. d. Ophthal. Gesellsch., p. 264, 1908. Heidelberg.

7. Stephenson. - The Ophthalmoscope, p. 13, 1910.

8. Remak. - Centralbl. f. prakt. A ugenheilk., p. 161, 1886.

9. van der Hoeve. - Brit. Jl. of Ophthal., March, 1924.

10. Wiegmann.-Klin. Monatsbl. f. Augenheilk., p. 161, 1886. .

11. Edinger.-Deutsche,med. Wochenschr., 1904 and 1905.

\section{CASE OF SUPERFICIAL AND DEEP LENS CHANGES, ASSOCIATED WITH DEPOSIT OF PIGMENT ON THE CENTRAL AREA OF THE ANTERIOR CAPSULE OF THE LENS}

\author{
BY \\ IoHn Foster, F.R.C.S.(Edin.) \\ WEST HARTLEPOOL
}

My excuse, if one be deemed necessary for reporting this case, is, that it is well known that there is a dearth of references in the matter of congenital abnormalities of the pupillary area. Probably, however, I should not have taken further note of this case, had I not seen, in this journal for June, 1922, a description of seven similar cases by Dr. Ernest Thomson. Anyone interested in this class of case would naturally refer to Dr. Thomson's paper, where the subject is well discussed, with opinions of several leaders in ophthalmology. Many references are given, British, American, and Continental; to these I have nothing to add.

\section{Notes of my case}

Dorothy M., 12 years of age, sent to the town ophthalmic clinic on account of defective sight. Record of vision: R.V.=6/18 2; L.V. $=6 / 18{ }^{3}$; no glass helped. Date January 10,1922 .

Condition under Atropin. Right Eye.-The central area of the pupil is occupied by an almost circular mass of brown pigment with two holes, below the centre, which the sketch shows; the rest of the pupillary area is normal and the edge of the iris is free from any abnormality whatever. Superior to the circular pigment mass, is a whitish radial spoke, sharply defined, with pointed end upwards, it is clearly subcapsular. 